\title{
Another side of using load cell to measure the viscosity of a cookie jam for home industries with the ATMega328 for monitoring purposes
}

\author{
Kurnia Brahmana $^{1 *}$, Takdir Tamba ${ }^{1}$ \\ ${ }^{1}$ Faculty of Mathematics and Natural Science, Universitas Sumatera Utara, Medan, Indonesia \\ *Email: kurnia1@usu.ac.id
}

\begin{abstract}
A simple structure to measure the viscosity of a cookie jam has been built. The purpose is to help home industries to judge the right time to stop heating and stirring. The value is used in order to get the optimum result of jam for a good taste and economically considered. The load cell is applied to measure the viscosity by fixing it to the stirrer wing and converting the viscosity directly as weight. The number of the viscosity is compared to the OIL SAE commercial standard number and programmed in the microcontroller to display the corresponding values as approximation. The structure and the system can be easily adapted for other kind of purposes with similar interest
\end{abstract}

Keyword: Industry, Vicosity

\section{INTRODUCTION}

In the process of making a cookie jam it takes a lot of effort such as energy for stirring, direct observing, and controlling the heat from the gas stove in order to make it good. An idea of measuring the right time to stop heating and stirring the jam never got into a close one until a load cell is included the sensor in the systemLoad Cell is supposed to use as weighing measurement sensor, but it can also be used to measure viscosity of a cookie jam, one side is fixed to stirrer and the other side is waved at the jam with an extra wing to sense the pressure as a weight.

Viscosity is not only important physical properties for larger food industry but also for small scale production of cookie jam. Thus it is a great help for home industries to be able to measure the right viscosity. The method that is used in this experiment is comparing the weight measured in the cookie jam to the measuring weight that is found when using industrial standard oil.

Base on the above analysis, in order to get an automatic control of observing the increasing of the viscosity a microcontroller is used to measure and to display the online viscosity of the cookie jam using the standard data from the known oil viscosity. The stirrer is designed to hold the load cell while moving in above the cookie jam while the wing side which is made of stainless steel materials is waving in the jam to produce a weight effect to the load cell and send the value to the microcontroller.

\section{METODOLOGY}

A suitable stirrer is designed to meet the bottom and cylinder side with the fixed load cell is shown in Fig. 1.(b) To stir the cookie jam the stirrer need about 6 to 8 RPM then the mechanics is constructed to consist of a gear box speed reducer of 50 to 1 ratio and about 5 to 1 gear ratio chain transmission to generate about 8 RPM from a 1440 RPM commercial $1 \frac{1}{2}$ HP AC motor. The rotational power is sent to the axle of the stirrer is shown in Fig. 1(a). The stirrer and the wing of the load cell are put through in the tank that will be filled with a light jam. The light jam may be consists of water, sugar, salt, pineapple juice, and some more ingredients. The gas stove is lighted below the tank and the flame is adjusted to give a moderate heat to the tank. The motor is started then the stirrer starts to stir and the wing of the load cell feels the weight of the torque more and 
Kurnia Brahmana, et.al. Another side of using load cell to measure the viscosity

more viscos as the time goes because of water evaporated out of the heated jam. The torque that is converted to weight is the measured as the viscosity of the jam.

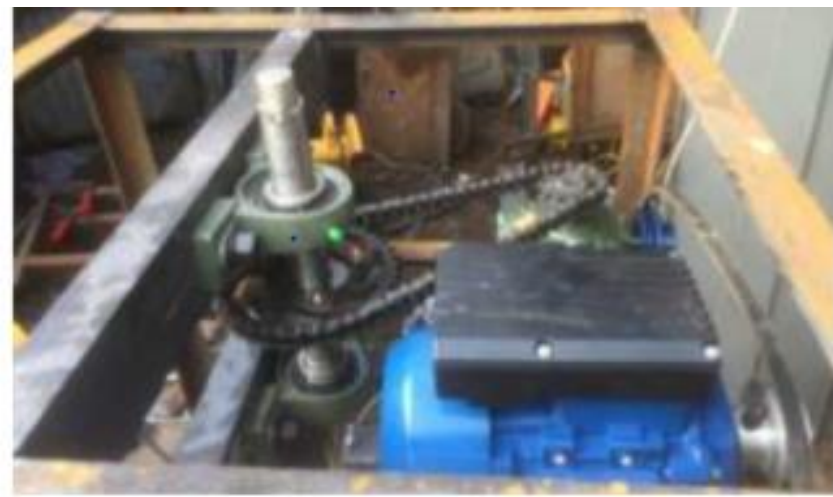

Figure 2.1 RPM speed reducer

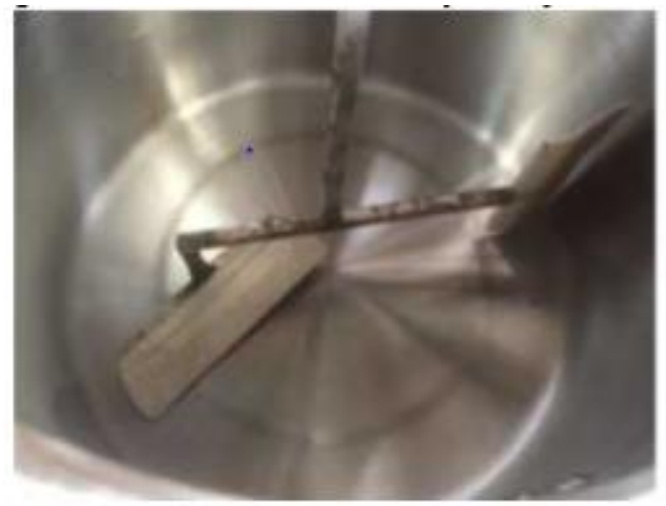

Figure 2.2 the stirrer model

The load cell is located at the vertical side of the stirrer wing and the microcontroller collected the value from the load cell on the go. Some information also shown in the LCD display such as the temperature and the RPM count to help the user to judge the closest time to stop stirring and shutting flaming of the tank from the LPG stove underneath the tank. Time is not considerably as the a decision parameter but the viscosity

\section{RESULT AND DISCUSSION}

The treatment is done by heating the oils in the tank to $1000 \mathrm{C}$, then the stirrer is run with the load cell wing in the Oil. The value of the viscosity will be measured as weight. Not all the oils with their viscosity shown in the Table 1 . were measured, because not all of them are available in the market.

\begin{tabular}{cc}
\hline SAE Viscosity Grade $\left[{ }^{\circ} \mathrm{C}\right]$ & $\begin{array}{c}\text { Min. Viscosity }\left[\mathrm{mm}^{2} / \mathrm{s}\right] \text { at } \\
100^{\circ} \mathrm{C}\end{array}$ \\
\hline $0 \mathrm{w}$ & 3.8 \\
$5 \mathrm{w}$ & 3.8 \\
$10 \mathrm{w}$ & 4.1 \\
$15 \mathrm{w}$ & 5.6 \\
20 & 5.6 \\
$20 \mathrm{w}$ & 5.6 \\
$25 \mathrm{w}$ & 9.3 \\
30 & 9.3 \\
40 & 12.5 \\
$40 \mathrm{w}$ & 12.5 \\
\hline
\end{tabular}


Kurnia Brahmana, et.al. Another side of using load cell to measure the viscosity

\begin{tabular}{cc}
\hline SAE Viscosity Grade $\left[{ }^{\circ} \mathrm{C}\right]$ & Min. Viscosity $\left[\mathrm{mm}^{2} / \mathrm{s}\right]$ at \\
& $100^{\circ} \mathrm{C}$ \\
\hline 50 & 16.3 \\
60 & 21.9 \\
\hline
\end{tabular}

Table 3.1Automotive lubricant viscosity grades: engine oils-SAE J 300, Dec. 1999 The viscosity seems increasingly to a quadratic polynomials to the weight and follows the equation below;

$$
y=0.278 x^{2}-1.200 x+5.105
$$

The load cell that is used in this work is the $5 \mathrm{~kg}$ load cell type interfaced with the HX711 module to the microcontroller. imply the work is just something like weighing things. With the application library provided by the "Adafruit" the code with Arduino can be as simple as the following. Since the code in the library produce a linear output then the equation above is added to the code.

\#include "HX711.h" //You must have this library in your arduino library folder

\#include <LiquidCrystal.h>

\#define DOUT 4

\#define CLK 6

HX711 scale(DOUT, CLK);

LiquidCrystal lcd $(6,7,2,3,4,5) ; / /$ pins that are connected to the lcd

char myBuffer[16] = "'; // width of LCD

void setup() \{ // put your setup code here, to run once:

scale.set_scale();

scale.tare(); //Reset the scale to 0

long zero_factor $=$ scale.read_average ()$; / / G e t$ a baseline reading

scale.set_scale(1000);

\}

void loop() \{ // put your main code here, to run repeatedly:

int berat $=$ scale.get_units () ;

float $\mathrm{v}=(0.278 *$ berat $*$ berat $)-(1.200 *$ berat $)+5.105$;

snprintf(myBuffer, sizeof(myBuffer), "V: \%03d.\%03d ", v/1000, v \% 1000);

lcd.setCursor $(0,1)$;

lcd.print(myBuffer);

delay (100);

\}

The weight that is represented as the viscosity can be seen on the LCD display, as the stirrer is stirring on the go. When the result is swing to much then the wing of load cell need to be trimmed a little bit. The following circuit Fig.2. is used in this work, the picture can be clicked to go to the link source to see more detail if needed.

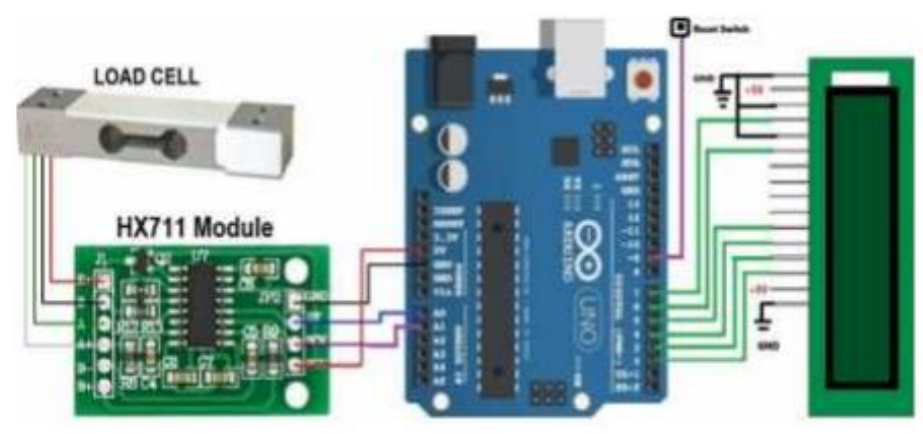

Figure 3.1 The complete circuit 
Commonly the load cell consist of four wires with legends Red to E+, Black to -, Green to A-, and White to A+ to be connected to the HX711 module while the CLK and the DT pin can be other active pins then stated them in the code. Similarly should be done to the 1602 type of LCD display to get a proper text as required.

\section{KESIMPULAN}

The structure and the design of the system is simple. But still good enough to measure the viscosity of a cookie jam and could be adapted for other kind of purposes that is similar to jam like producing rice jelly. Through the detail of the circuit and the code, it can be built easily even for the amateur one. The viscosity shown on line when the system is working can be used to judge the right time when to stop heating and stirring the jam. This kind of using load cell can also be adapted to other kind of interest.

\section{UCAPAN TERIMAKASIH}

We wish to extend our sincere gratitude to the Universitas Sumatera Utara for giving us valuable guidance and funding via NON PNBP Universitas Sumatera Utara to complete this first phase of project successfully with contract number: 327/UN5.2.3.2.1/PPM/2019. We also extend our sincere thanks to Dr. Saharman Gea for his valuable support and guidance. Finally thanks to our friends Dr. Perdinan Sinuhaji and Dr. Kerista Tarigan and the Digital Lab. Crews who had supported us whole heartedly during the presentation of this report.

\section{DAFTAR PUSTAKA}

Bin Li, Wang Yu. 2012. A New Method for on-Line Measurement of Viscosity. International Workshop on Information and Electronics Engineering. China: Faculty of Chemical Engineering Kunming University of Science and Technology

Chen, Huizhao. 1994. Viscosity Measurement. Beijing: China Metrology Press

Cheng Weijun, Xu Sixin. 2001. Sucrose-crystallizing and Suger. Beijing: China Light Indutry Press.

Fleischhauer, Eric \& Dahlberg, Jerry \& Solomon, Jason \& Keanini, Russell \& T Tkacik, Peter. (2019). Kinematic viscosity measurement of granular flows via low reynolds number cylinder drag experiment. Measurement Science and Technology. 10.1088/13616501/ab08cf.

Höhlein, Stephan, dkk. 2018. Viscosity Measurements with the IMETER. Rheometry Workshop. Freiburg.

Tong Gang, Cheng Lijun and Leng Jian. 2007. A Review on Rotary Viscometer. Automation Panorma. (2),67-70.

Xiaofeng Lin, H. Zhang, Li Wei and Huixia Liu, "Optimal control for industrial sucrose crystallization with action dependent heuristic dynamic programming," 2010 8th World Congress on Intelligent Control and Automation, Jinan, 2010, pp. 656-661.

Zheng Yingna, Li Changxi and Fan Xinrui. 1994. Study on Real Time Massecuite Supersataration Measuring Apparatus. Journal of electronic measurement and instrument. 2(8),53-59. 
ISSN Printed Version: 2549-4341

ISSN Online Version: 2549-418X

ABDIMAS TALENTA 4 (2) 2019: 525-529

http://abdimas.usu.ac.id

Kurnia Brahmana, et.al. Another side of using load cell to measure the viscosity

Zhou Jun, Liu Chengliang. 2007. Load Cell Design for Parallel Beam Impact-based Grain Mass Sensor. Journal of Agricultural Engineering. 23(4), 110-114. 